This item was submitted to Loughborough's Research Repository by the author.

Items in Figshare are protected by copyright, with all rights reserved, unless otherwise indicated.

\title{
The relationship between psychological well- and ill-being, and perceived autonomy supportive and controlling interpersonal styles: A longitudinal study of sport coaches
}

\section{PLEASE CITE THE PUBLISHED VERSION}

http://dx.doi.org/10.1016/j.psychsport.2015.02.002

\section{PUBLISHER}

(C) Elsevier B.V.

\section{VERSION}

AM (Accepted Manuscript)

\section{PUBLISHER STATEMENT}

This work is made available according to the conditions of the Creative Commons Attribution-NonCommercialNoDerivatives 4.0 International (CC BY-NC-ND 4.0) licence. Full details of this licence are available at: https://creativecommons.org/licenses/by-nc-nd/4.0/

\section{LICENCE}

CC BY-NC-ND 4.0

\section{REPOSITORY RECORD}

Stebbings, Juliette, Ian Taylor, and Christopher Spray. 2015. "The Relationship Between Psychological Welland III-being, and Perceived Autonomy Supportive and Controlling Interpersonal Styles: A Longitudinal Study of Sport Coaches". Loughborough University. https://hdl.handle.net/2134/17464. 
Running head: COACHES' PSYCHOLOGICAL HEALTH AND INTERPERSONAL STYLES

1

2

3

4

5

6

7

8

9
Date of Submission: 23 ${ }^{\text {rd }}$ June, 2014

Date of resubmission: $11^{\text {th }}$ November, 2014

Date of resubmission: $15^{\text {th }}$ February, 2015 


\section{Abstract}

2 The present study longitudinally explored sports coaches' psychological well-being (positive

3 affect and integration of coaching with one's sense of self) and ill-being (negative affect and

4 devaluation of coaching) as predictors of their perceived autonomy supportive and

5 controlling interpersonal styles towards individuals under their instruction. Participants were

6195 sport coaches who completed questionnaire measures at three time points across an

7 eleven-month period. Controlling for social desirability, multilevel analyses revealed that

8 within-person increases and individual differences in positive affect and integration were

9 positively associated with autonomy support. Conversely, within-person increases and

10 individual differences in negative affect, but not devaluation, were associated with increased use of interpersonal control. The indicators of well-being did not predict interpersonal control and the indicators of ill-being did not predict autonomy support. In their entirety, the present findings suggest that autonomy supportive and controlling interpersonal styles have unique correlates, and affective determinants may play a particularly central role in controlling interpersonal styles. Supporting the psychological health of coaches may lead them to create an adaptive interpersonal environment for their athletes. 
The relationship between psychological well- and ill-being, and perceived autonomy supportive and controlling interpersonal styles: A longitudinal study of sport coaches. Considerable research has attempted to identify the components of psychological well-being and pinpoint its antecedents within a range of life domains, including education, parenting, sport, and physical activity (e.g., Diener, 2000; Quested \& Duda, 2011; Ryan \& Deci, 2001; Ryff et al., 2006; Standage, Duda, \& Ntoumanis, 2005).

This research agenda has, however, typically regarded psychological well-being as the end product, while less attention has been given to potential outcomes of this optimal state. In the current study we adopted the self-determination theory (SDT; Deci \& Ryan, 2000) framework in order to examine whether indices of psychological well- and ill-being reported by sports coaches were related to their perceived autonomy supportive and controlling interpersonal styles towards athletes under their instruction. The coaching domain is one in which these research questions are particularly salient because the benefits for athletes of receiving autonomy support are manifold (see Amorose, 2007, for a review), yet controlling coaching styles remain evident (e.g., Fraser-Thomas \& Côté, 2009). In addition, psychological ill-being in various forms is particularly prevalent in sport coaches, for example, negative affect (Stebbings, Taylor, Spray, \& Ntoumanis, 2012), burnout (Goodger, Gorely, Lavellee, \& Harwood, 2007), stress (Olusoga, Butt, Hayes \& Maynard, 2009), and dissatisfaction (Dixon \& Warner, 2010) have been reported by coaches. It is important, therefore to assess the potential effects this may have on interpersonal interactions.

\section{The SDT Perspective on Interpersonal Styles}

The investigation of coaches’ behavior towards athletes has attracted considerable research attention. Within SDT, primary attention has been given to autonomy supportive and controlling interpersonal styles (Vallerand \& Losier, 1999). Coaches create an autonomy supportive environment when they facilitate athletes' sense of volition and causality by 
1 acknowledging their feelings and perspectives, highlighting the value of an activity, and

2 demonstrating confidence in their abilities. Observational research conducted in educational settings has also demonstrated an autonomy supportive style to include praising improvement and mastery, encouraging effort, and responding positively to questions (Reeve, Bolt, \& Cai, 1999; Reeve \& Jang, 2006). Conversely, behaviors characteristic of a controlling interpersonal style include seeking compliance, withdrawal of time and attention, coercion, criticism, punishment, task-contingent rewards, and the provision of feedback to manipulate subordinates’ thoughts and behaviors (Bartholomew, Ntoumanis, \& Thøgersen-Ntoumani, 2009; Reeve, Jang, Carrell, Jeon, \& Barch, 2004). Previous research has pointed towards the independence of autonomy support and control in light of small negative associations between the constructs, and their distinct psychological correlates (Bartholomew, Ntoumanis, Ryan, Bosch, \& Thøgersen-Ntoumani, 2011; Pelletier, Fortier, Vallerand, \& Brière, 2001; Silk, Morris, Kanaya, \& Steinberg, 2003)

Considerable research has demonstrated the advantages of coach autonomy support (e.g., Adie, Duda, \& Ntoumanis, 2012; Gagné, Ryan, \& Bargmann, 2003; Quested \& Duda, 2011) and the deleterious effects of coaches’ controlling strategies on their athletes (e.g., Bartholomew, et al., 2011). This evidence implies that an autonomy supportive style should be promoted, whereas a controlling style should be discouraged. This literature, however, has typically considered the athletes as the central group of interest, and only assessed athletebased variables (i.e., athlete perceptions of coach behavior, and athletes’ well-/ill-being). Research has been less forthcoming that addresses coach-related factors as reasons why coaches engage in these contrasting interpersonal styles. There are many plausible factors, such as the coach's personal orientation, the coaching context, and athletes' behaviors and motivation (Mageau \& Vallerand, 2003). Whilst these variables have received some research consideration, one other likely correlate is the coaches’ psychological health. 


\section{$1 \quad$ Psychological Well-Being and Ill-Being}

Numerous operationalisations of psychological health exist, yet considerable attention

has been focused upon two key perspectives; the hedonic approach and the eudaimonic approach (Ryan \& Deci, 2001). The hedonic tradition of well-being focuses on the attainment of happiness, and seeks to understand "what makes experience and life pleasant and unpleasant” (Kahneman, Diener, \& Schwarz, 1999, p. ix). Consistent with this standpoint, early research (e.g., Andrews \& Withey, 1976; Bradburn, 1969) conceptualised psychological well-being as a range of positive emotional experiences or moods (e.g., happiness, pleasure, interest, enthusiasm and inspiration); collectively termed positive affect (Diener, 2000). On the other hand, psychological ill-being is acknowledged as a separate, independent dimension of psychological functioning (Watson, Tellegen, \& Clark, 1988; Ryff, et al., 2006), often associated with discrete predictors than that of well-being (Adie, Duda, \& Ntoumanis, 2008, Bartholomew et al., 2011; Sheldon, \& Bettencourt, 2002). From the hedonic tradition, psychological ill-being is reflected, not in the absence of positive affect, but in the overt experience of negative affect, such as distress, nervousness, anger, and aversion (Watson, et al., 1988).

Despite the value of assessing well-being in terms of pleasure and happiness, this hedonic standpoint has been criticized as being limited in scope. From Greek philosophers to modern psychological theorists, many contend that human psychological well-being encompasses more than the presence of positive affect and the absence of negative affect (Ryan \& Deci, 2001). Rather, the eudaimonic approach is concerned with human growth and actualisation of potential. In order for individuals to experience eudaimonia, they must engage in activities that are personally expressive and congruent with their true sense of self (Waterman, 1993). In contrast to this integrated functioning, the concept of devaluation represents a sense of detachment from an activity (Raedeke, 1997). Researchers have 
differentiated between this eudaimonic perspective and hedonic components of well-being in their discussions on psychological health (e.g., Mack et al., 2011; Gunnell, Crocker, Mack, Wilson, \& Zumbo, 2014). As such, positive affect and integrated functioning are indicative of healthy psychological experience, whereas, negative affect, and devaluation of an activity are representative of psychological malfunction (Ryan \& Deci, 2001).

\section{Psychological Well- and Ill-Being and Interpersonal Styles}

In a recent cross-sectional study, Stebbings, et al. (2012) reported that sports coaches' psychological well-being was significantly associated with the provision of autonomy support towards their athletes, whereas coaches’ psychological ill-being was associated with their use of controlling interpersonal behaviors. These authors, however, operationalised psychological well- and ill-being as composite factors inclusive of a range of hedonic and eudaimonic indicators, including positive affect, subjective vitality, negative affect and emotional and physical exhaustion. As such, the present study is the first to examine the relative contributions of the different components of well- and ill-being and offer insight into the most important psychological correlates of perceived interpersonal behavior. No previous research has undertaken this task; however, indirect evidence suggests relations among different elements of well-being and interpersonal behavior. For instance, a positive affective state (i.e., hedonic well-being) has been associated with helping and altruism, persuasive communication, and negotiating. In addition, people in a positive mood may be more likely to be empathic towards others. On the other hand, individuals in a negative mood have been rated by others as more defensive, critical, and less friendly and cooperative (see Forgas, 2002, for a review).

There is a scarcity of research examining the relationship between eudaimonic integrated functioning and interpersonal behavior. Research in the educational domain has, however, linked teachers' self-determined and internalized motivations, as well as their 
1 degree of engagement with their role, with their use of adaptive interpersonal teaching and

2 leadership strategies (Klussman, Trautwein, Lüdtke, \& Baumert, 2008; Roth, Assor, Kant-

3 Maymon, \& Kaplan, 2007; Taylor, Ntoumanis, \& Standage, 2008; Trepanier, Fernet, \&

4 Austin, 2012). For example, Trepanier and colleagues (2012) reported a link between school

5 principals' autonomous motivation for work and their adaptive transformational leadership

6 style. In addition, Taylor et al. (2008) speculated that autonomy supportive teaching

7 strategies require one to invest personal effort into teaching and are, therefore, more likely if

8 teaching is personally expressive and integrated into the essence of one's self. Indicators of eudaimonic ill-being have similarly been associated with poor quality interpersonal behavior. For example, research has indicated that when teachers experience pressure to comply with set curricula and colleagues' teaching methods, and are evaluated based on student performance standards, they become less-self-determined in their work, and adopt a more controlling interpersonal style with students (e.g., Deci. Spiegel, Ryan, Koestner, \& Kauffman, 1982; Pelletier, Séguin-Lévesque, \& Legault, 2002). In addition, teachers' and sports coaches suffering with symptoms of burnout have been associated with the use of psychological controlling and autocratic instructional strategies (Soenens, Sierens, Vansteenkiste, Dochy, \& Goossens, 2012; Vealey, Armstrong, Comar, \& Greenleaf, 1998).

\section{Summary and Hypotheses}

A wealth of research has examined the effects of coaches' autonomy supportive and controlling behavior on athletes, yet very little has explicitly examined coaches’ psychological well- and ill-being as potential precursors of these interpersonal styles. The present study aimed to fill this research gap and build on current knowledge in a number of ways. First, Stebbings et al. (2012) proposed that two separate processes exist in which psychological well-being and ill-being were differentially predictive of autonomy support and control, respectively. However, they did not explicitly test the associations between well- 
1 being and control, and ill-being and autonomy support, therefore, we addressed this

2 limitation. Second, we examined both hedonic and eudaimonic indices of well- and ill-being separately, as the indicators employed by Stebbings and colleagues were used to form overall

4 composite factors. Third, the indirect evidence reviewed above was cross-sectional, hence,

5 longitudinal research is warranted to clarify the temporal dynamics of these relationships. .

6 One important benefit of longitudinal research is the disaggregation of within person

7 fluctuations and individual change, and identifying both types of relationships has important

8 theoretical implications (Curran \& Bauer, 2011; Raudenbush \& Bryk, 2002). This can only

9 be done using longitudinal research over a minimum of three time points (Rogasa, 1995;

10 Singer \& Willett, 2003). The present study aimed to achieve this by exploring whether

11 individual differences and within-person fluctuations in psychological well- and ill-being were related to perceived autonomy support and control. This disaggregation of effects is an important extension to the literature because it may help to identify individuals who may be prone to employing specific behavioral styles, as well as the potential effects of temporal changes in well- and ill-being on behavior. Finally, it is plausible that more experienced coaches are more consistent in their behavior and, therefore, are less influenced by their wellor ill-being, compared to newer coaches. On the other hand, factors such as the novelty of coaching roles or enthusiasm for coaching may override influences of psychological health in less experienced coaches. Therefore, to test these contrasting speculations, we investigated whether any observed relationships varied depending on the coaching experience of the participants.

It was hypothesised that positive affect and integration would predict autonomy support at both levels of analysis, and that negative affect and devaluation would predict control at both levels of analysis. Due to the independence of the autonomy support and control, and well- and ill-being constructs, it was expected that the two indices of ill-being 
1 (negative affect and devaluation) would not be significantly associated with autonomy

support, and the two indices of well-being would not be significantly associated with control.

We also included a measure of social desirability as a covariate to account for the possibility that items regarding coaches' interpersonal behavior may be susceptible to socially desirable responses. As described above, it is not clear how coaching experience might influence observed relationships between the study variables, therefore, we made no a priori predictions regarding this aspect of the study.

\section{Method}

\section{Participants and Procedures}

Following approval from a university ethics committee, the study was conducted in accordance with APA guidelines. Data collection occurred at three time points, with time points two and three approximately five and eleven months after time point one, respectively. Examining the study variables (particularly indices of eudaimonic health and interpersonal behaviors) over a relatively long time was required to allow these potentially more robust variables to change.

Prior to data collection, invitation emails were sent out by national governing bodies to coaches on behalf of the research authors. Coaches who provided informed consent responded to an online multi-section questionnaire that took approximately 15 minutes to complete. At the end of the questionnaire, participants were asked to provide an email address if they wished to complete the study at time points two and three. Email addresses were not associated with the data collected - coaches’ initials and age were used to match responses across time points.

Participants were 195 coaches from the United Kingdom (154 male, 41 female; $M$ age $=46.24$ years, $S D=13.26$, range $=18-75)$, comprising 119 coaches who completed the measures at all three time points, and 76 who completed the measures twice. Data from all 
1195 coaches were included in the analyses and all variables were measured at all time points.

2 The coaches reported being involved in one of 26 sports, operating at the recreational $(n=$ 20), club ( $n=81)$, regional $(n=37)$, national $(n=41)$, and international/professional $(n=16)$

4 levels. Coaches had, on average, 14.91 years $(S D=10.99)$ years of coaching experience and spent $11.93(S D=10.60)$ hours per week coaching. Coaches reported their job status as either paid full-time $(n=25)$ paid part-time $(n=63)$, voluntary full-time $(n=8)$, voluntary parttime $(n=74)$ or a combination of the above $(n=25)$.

\section{Measures}

Positive and negative affect. Positive and negative affect were assessed using the Positive And Negative Affect Schedule (Watson, et al., 1988), which comprises two 10-item subscales. Coaches indicated the degree to which they had experienced positive (e.g., “Enthusiastic”, "Proud”, and “Excited”) and negative (e.g., "Nervous”, “Upset”, and "Distressed") emotions whilst coaching during the last month on a five-point scale ranging from 1 (not at all or very slightly) to 5 (extremely). Researchers have reported factorial validity, internal consistency, and test-retest reliability of the subscales in samples of undergraduate students (Watson et al., 1988) and sport coaches (Stebbings et al., 2012).

Integration. To assess the extent to which coaching was personally expressive and congruent with the coaches' sense of self over the previous month, the integration subscale of the Work Motivation Inventory (WMI; Blais, Lachance, Vallerand, Brière, \& Riddle, 1993) was adapted to the coaching context. The items were preceded by the question "Why do you coach...?” and required coaches to rate five items (e.g., "Because it has become a fundamental part of whom I am”, "Because by being a coach, I am living in line with my deepest principles”) on a scale ranging from 1 (does not correspond at all) to 7 (corresponds exactly). The WMI has not been used in coaching contexts previously; however, it has been adapted to physical education teaching contexts (e.g., Taylor et al., 2008). 
Devaluation. Coaches' levels of devaluation were assessed using the five-item

Devaluation subscale of the Athlete Burnout Questionnaire (Raedeke \& Smith, 2001), adapted to the coaching context. Coaches were asked to reflect on their experiences over the last month, and rate the frequency of which they had experienced devaluation (e.g., "The effort I spend coaching would be better spent doing other things”) on a five-point scale anchored by 1 (almost never) to 5 (most of the time). The scale authors report internal consistency, factorial structure and test-retest reliability with an athlete population.

Autonomy support. Coaches’ perceptions of their autonomy supportive style was

measured using the six-item version of the Health Care Climate Questionnaire (HCCQ;

Williams, Grow, Freedman, Ryan, \& Deci, 1996), adapted to the sport context. Coaches were asked to consider their coaching practices over the last month, and rate the degree to which they agreed with each of the items (e.g., "I provide my athletes with choices and options") on a seven-point scale ranging from 1 (strongly disagree) to 7 (strongly agree). Previous research has adapted the six-item HCCQ to assess coaches’ perceptions of their autonomy support, and demonstrated internal consistency and factorial validity (Stebbings et al., 2012). Controlling behavior. The 15-item Controlling Coach Behaviors Scale (CCBS; Bartholomew, Ntoumanis, \& Thøgersen-Ntoumani, 2010), adapted to reflect a coach’s perspective, was employed to assess coaches’ perceptions of their controlling interpersonal style over the previous month. The scale measures four types of controlling behaviors, including controlling use of rewards (e.g., "I try to motivate my athletes by promising to reward them if they do well”), negative conditional regard (e.g., "I am less friendly with my athletes if they don't make an effort to see things my way”), intimidation (e.g., "I embarrass my athletes in front of others if they do not do certain things”), and excessive personal control (e.g., “I try to interfere in aspects of my athletes’ lives outside of sport”), anchored by 1(strongly disagree) and 7 (strongly agree). Previous research that modified the CCBS items 
1 to reflect a coach's perspective has found the scale to possess internal consistency and

2 factorial validity (Stebbings et al., 2012).

Social desirability. Participants' tendency to respond to items in a socially desirable manner was assessed using a short form of the Marlowe-Crowne Social Desirability Scale (Strahan \& Gerbasi, 1972). Participants were required to rate 10 items as either true or false (e.g., “I am always willing to admit when I make a mistake”). A socially desirable response carried a weighting of one, with a non-socially desirable answer scoring zero. The scores were then summed to produce a social desirability score for each participant. Previous research has demonstrated the scale’s validity (Reynolds, 1982).

\section{Results}

Table 1 presents the descriptive statistics and Cronbach’s alpha coefficients for each of the study variables at each time point. All subscales demonstrated excellent internal reliability $(\alpha>.80)$, with the exception of the social desirability measure $(\alpha \geq .56)$. We nonetheless retained the measure because social desirability was not directly related to the study hypotheses, but was simply included as a control variable.

Participants generally reported levels of positive affect, integration and autonomy support above the midpoint of the respective scales, and levels of negative affect, devaluation, and controlling behaviors below the midpoint of the respective scales.

\section{Approximate location of Table 1.}

The primary analyses were conducted by performing a series of multilevel regression models using MLwiN software (version 2.25; Rasbash, Browne, Healy, Cameron, \& Charlton, 2012). Multilevel analysis is the preferred option when data are hierarchically structured (Hox, 2010), such as in the present study, where the repeated measures (level 1) were nested within individuals (level 2). In line with our research aims, multilevel analysis 
1 also allowed us to simultaneously estimate within-person fluctuations and individual

2 differences.

Prior to entering predictor variables into the models, intercept-only models were constructed to identify the intraclass coefficients (ICCs) for each variable (shown in Table 1), which represented the proportion of variance at the individual difference level, compared to the total variance. Multilevel modelling is warranted when significant variance exists at the within-person and individual difference levels (Hox, 2010). Between $62 \%$ and $70 \%$ of the variance in the study variables was attributable to the individual difference level (therefore, between $30 \%$ and $38 \%$ was attributable to the within-person level).

Models were also tested with demographic variables (gender, age, sport type, competitive level, coaching experience, and hours per week coaching) and social desirability entered into level 2 equations as predictors of autonomy support and control. Gender and type of sport were coded as dummy variables (gender: $0=$ female, $1=$ male; type of sport: $0=$ individual, 1 = team). Coaches of team sports, compared to individual sports, reported providing significantly less autonomy support $(\beta=-.23, p<.05)$ and greater use of control ( $\beta$ $=.42, p<.001)$. Years of coaching experience $(\beta=.19, p<.01)$ and hours per week spent coaching $(\beta=.19, p<.001)$, were also positively related to greater use of autonomy support. Social desirability bias showed significant positive associations with autonomy support $(\beta=$ $.21, p<.001)$, and significant negative associations with control $(\beta=-.16, p<.01)$. Sport type, coaching experience, hours per week coaching, and social desirability were therefore entered into the multilevel regression model for autonomy support, and sport type and social desirability were entered into the model for control, to control for any potential confounding effects.

Two conditional models were subsequently estimated to explore the primary research questions. To examine whether fluctuations in coaches' well- and ill-being were associated 
1 with their perceived provision of autonomy support and control (i.e., within-person effects),

2 the time-varying indices of well- and ill-being were entered into the level 1 equation of the

3 respective models. Each predictor was centred on the unique mean for each individual (i.e.,

4 group mean centering; Raudenbush \& Bryk, 2002). Further, to assess whether individual

5 differences in well- and ill-being were associated with autonomy support and control,

6 participants' scores for each predictor averaged across time were centred on the sample mean

7 (i.e., grand mean centred) and entered into the level 2 equation in each model. Within these

8 conditional models we tested whether the relationships among predictor variables and

9 dependent variable were constant across coaches (i.e., fixed effects) or varied (i.e., random

10 effects) by examining the significance of the level 2 variance term when the slope was

11 allowed to vary, as well as the difference in deviance between the fixed effects model and the random effects model (Hox, 2010). In an attempt to explain any observed random effects, we ran exploratory models with coaching experience predicting the slopes describing the relationship between the predictor and outcome variable (i.e., coaching experience $\times$ predictor interaction terms included). Results of these conditional models are shown in Table 2 and summarized below.

Approximate location of Table 2

Model A explored the effects of coaches’ well-being (positive affect and integration), and ill-being (negative affect and devaluation) on coaches' perceived provision of autonomy support at the within-person and individual difference levels. Results indicated that increases in positive affect and integration beyond one's normal levels were associated with greater perceived use of autonomy supportive strategies, however, the latter relationship varied across coaches $\left(\Delta \chi^{2}=23.93, p<.001\right)$. Moreover, coaches with generally high levels of positive affect and integration reported greater autonomy support, compared to those coaches 
1 with lower levels of positive affect and integration. Negative affect and devaluation

2 demonstrated no significant associations with autonomy support.

In light of the significant random effect found for the relationship between withinperson changes in integration and autonomy support, we constructed a model with coaching experience entered as a predictor of the slope of this relationship, which was found to be significant $(b=-.11, p<.05)$. Using techniques outlined by Curran, Bauer, and Willoughby (2006), it was established that the relationship between fluctuations in integration and autonomy support was significant for less experienced coaches $(b=1.40, p<.05)$, but not for more experienced coaches $(b=-1.08, p>.05)$.

Model B explored the effects of coaches' well-being (positive affect and integration), and ill-being (negative affect and devaluation) on coaches perceived controlling behavior at the within-person and individual difference levels. Increases in negative affect beyond one’s normal levels were associated with greater perceived controlling behavior, however, this relationship varied across coaches $\left(\Delta \chi^{2}=6.06, p<.05\right)$. In addition, coaches with generally high levels of negative affect reported greater controlling behaviors, compared to those coaches with lower levels of negative affect. No within-person or individual difference relationships were found for devaluation, positive affect or integration.

In view of the significant random effect found for the relationship between withinperson changes in negative affect and control, we constructed a model with coaching experience entered as a predictor of the slope of this relationship, which was found to be significant $(b=.12, p<.05)$. Subsequent analysis of this interaction indicated that the relationship between fluctuations in negative affect and control was significant for more experienced coaches $(b=1.41, p<.05)$, but not for less experienced coaches $(b=-1.16, p>$ $.05)$.

\section{Discussion}


The purpose of the present study was to examine the differential effects of both hedonic and eudaimonic indicators of psychological well- and ill-being on perceived autonomy supportive and controlling interpersonal styles. Using a longitudinal design, we were also able to decompose these relationships into within-person and individual difference levels. Controlling for socially desirable responses, coaching experience, hours per week spent coaching, and differences between coaching individual and team sports, the present study offers a number of significant advances to the existing literature.

Consistent with our hypothesis, hedonic well-being was found to be positively associated with the perceived provision of autonomy support at both the within-person and individual difference levels. That is, a coach who is happier and more excited (for example) than normal, may be more likely to provide greater opportunities for athletes under their instruction to express their values and beliefs, compared to when he or she is less happy and excited. Moreover, coaches who experience generally higher levels of positive affect may be more likely to convey confidence in their athletes' abilities and encourage athletes to ask questions, compared to coaches without this attribute. On the other hand, negative affect was significantly associated with more experienced coaches' interpersonal control at the withinperson level, and for all coaches at the individual difference level. In other words, a coach who becomes more irritable and upset (for example), may be more likely to criticize, intimidate, and coerce their athletes more than usual. Additionally, coaches who are prone to greater levels of negative affect may be more susceptible to employing a controlling behavioral style, compared to coaches generally experiencing lower levels. These findings extend previous research (e.g., see Forgas, 2002, for a review) by providing new insight into the within-person and individual difference processes linking hedonic psychological health and interpersonal behavior, and offers two major applied implications. First, individuals in coaching positions need to be made aware that fluctuations 
1 in their affective state may influence how they interact with their athletes. It may be

2 worthwhile, therefore, to provide self-awareness and emotional regulation training within coaching settings. For example, coaches could plan to some degree to engage in the interpersonal elements of their job (where high autonomy support and low control are central) during periods when they are most likely to be in a positive affective state (e.g., after a lunch break). Other non-interpersonal aspects of the coaching role, such as administrative tasks, could be undertaken when coaches are less likely to be in a positive affective state. Moreover, techniques commonly employed in alternative psychological settings, such as mindfulness techniques (e.g., Baer, 2003), could be adapted to assist coaches in minimizing the impact of negative affect on their interpersonal style.

With respect to eudaimonic well-being, increasing less experienced coaches’ feelings of integration beyond one's average state was associated with higher reported autonomy support. In addition, all coaches who generally considered their coaching role to be fully integrated into their sense of self, (e.g., I 'am' a coach, as opposed to coaching being something I just 'do’) may be more likely to engage in autonomy supportive coaching, compared to coaches reporting lower integration between coaching and the self. This finding extends previous research (e.g., Klussman et al., 2008; Roth et al., 2007; Taylor et al., 2008), in which internalised motives and engagement towards teaching were related to adaptive classroom behaviors. Individuals responsible for managing coaches (e.g., head coaches, sports club management, performance directors) could facilitate the internalization process by providing coaches with feedback and opportunities for training courses, allowing input into how coaches develop athletes, and providing opportunities to develop networks with other coaches. In addition, as highlighted by Taylor et al. (2008), autonomy supportive strategies require the investment of effort, therefore, when coaches experience a sense of congruence between their coaching role and their personal values, this may empower them with more 
1 energy to invest personal time and effort into that role. This implies that performance directors, head coaches and other employers of coaches should allow coaches the freedom to express their ideas and work in accordance with their values and beliefs. This can be achieved by providing choice and avoiding strict regulation of management and leadership strategies. In contrast to our initial hypothesis, however, devaluation did not emerge as a significant predictor of a controlling interpersonal style. It may be that when coaches devalue their coaching role, they adopt a laissez-faire approach to their coaching, rather than a controlling style. Indeed, research in the education context suggests that teacher's psychological ill-being, in the shape of symptoms of burnout, is linked with a lack of energy, enthusiasm, persistence, and willingness to invest effort into their work (i.e. a lack of engagement; Hakanen, Bakker, \& Schaufeli, 2006). Hence, a coach who devalues their role, and feels as if their effort would be better spent engaged in other activities, may reduce interpersonal effort by abdicating responsibilities, avoiding making decisions, and being absent when needed. Future research is required to assess this style of interpersonal behavior, and its distinct antecedents. al.’s (2012) argument for distinct adaptive and maladaptive processes that facilitate autonomy support and control. Specifically, we found no support for associations between psychological well-being and a controlling style, nor psychological ill-being and an autonomy supportive style. Researchers should consider these divergent processes when exploring potential antecedents of interpersonal behavior. The findings can also be extended in several ways. First, only two markers of hedonic and eudaimonic well- and ill-being were assessed, however, numerous other indices (e.g., subjective vitality, Ryan \& Frederick, 2001; life satisfaction; Diener, 1994) could be used to assess the individual and interactive effects of a wider range of determinants on interpersonal 
1 behavior. Similarly, other aspects of positive interpersonal behavior should be explored, such

2 as the provision of structure and interpersonal involvement (Ryan \& Deci, 2002). Previous

3 research has tended to combine scores on all three dimensions of interpersonal style into

4 composite 'psychological need support' scores (e.g., Ntoumanis, 2005), whereas future

5 research could address the differential and cumulative effects of the three interpersonal

6 dimensions. Third, research could assess daily fluctuations in well-/ill-being, alongside

7 fluctuations in interpersonal behavior, to better assess how these relationships function at the

8 state-level on a day-to-day basis, or within and across training sessions. Fourth, interventions

9 or lab-based experimental research aimed at manipulating coaches' behavior via their

10 psychological well- and ill-being would be a useful addition to the extant literature. Such

11 research designs offer the benefits of high internal reliability and validity, and would allow causality in the relationships to be determined (Thomas, Nelson, \& Silverman, 2011). In addition, athlete reports of coach behavior and observational data is warranted to more fully and objectively assess coach interpersonal behavior. These alternative methodologies would counteract the use of entirely self-report data within the present study, which may have given rise to common method variance partially accounting for our findings (although the existence of this statistical artefact is contentious; Spector, 2006). Last, in addition to psychological well- and ill-being, alternative variables could be assessed as potential predictors of interpersonal behavior. For example, the SDT-based goal content mini theory (Vansteenkiste, Niemiec, \& Soenens, 2010) distinguishes between intrinsic (e.g., personal growth, community contribution) and extrinsic (e.g., money, fame, image) goals. Future research could examine the extent to which coaches' personal goals (whether at the global or contextual level) impact upon interactions with their athletes.

\section{Conclusions}


The present study represents the primary attempt to delineate the differential effects of

2 indices of well- and ill-being on coaches' autonomy supportive and controlling interpersonal

3 behaviors over time. The results extend previous literature by decomposing the within-person

4 and individual difference relationships between psychological health and interpersonal

5 behavior. The current research also highlights the potential existence of two distinct

6 mechanisms by demonstrating that psychological well-being was unrelated to control, and ill-

7 being was unrelated to autonomy support. Overall, the present findings suggest that

8 supporting coaches so that they can experience positive affect and integration (and limit their

9 experience of negative affect) may lead them to create an adaptive interpersonal environment

10 (i.e., autonomy supportive, non-controlling), allowing athletes under their instruction to

11 flourish. Interventions based upon these findings could target the employers of sport coaches

12 (e.g., head coaches. performance directors, governing bodies) to sustain coaches’

13 psychological health, and also target the coaches themselves to promote an awareness of how

14 their own well-/ill-being might affect their interpersonal behavior towards athletes. 


\section{References}

Adie, J. W., Duda, J. L., \& Ntoumanis, N. (2008). Autonomy support, basic need satisfaction and the optimal functioning of adult male and female sport participants: A test of basic needs theory. Motivation and Emotion, 32, 189-199. doi:10.1007/11031-008-9095-z

Adie, J. W., Duda, J. L., \& Ntoumanis, N. (2012). Perceived coach autonomy support, basic need satisfaction and the well- and ill-being of elite youth soccer players: A longitudinal investigation. Psychology of Sport and Exercise, 13, 51-59. doi:10.1016/j.psychsport.2011.07.008

Amorose, A. J. (2007). Coaching effectiveness. In M. S. Hagger \& N. L. D. Chatzisarantis (Eds.), Intrinsic motivation and self-determination in exercise and sport (pp. 209-227). Leeds: Human Kinetics.

Andrews, F. M., \& Withey, S. B. (1976). Social indicators of well-being. New York: Plenum Press.

Baer, R. A. (2003). Mindfulness training as a clinical intervention: A conceptual and empirical review. Clinical Psychology: Science and Practice, 20, 125-143. doi:10.1093/clipsy.bpg015

Bartholomew, K. J., Ntoumanis, N., Ryan, R. M., Bosch, J. A., \& Thøgersen-Ntoumani, C. (2011). Self-determination theory and diminished functioning: The role of interpersonal control and psychological need thwarting. Personality and Social Psychology Bulletin, 37, 1459-1473. doi:10.1177/0146167211413125

Bartholomew, K., Ntoumanis, N., \& Thøgersen-Ntoumani, C. (2009). A review of controlling motivational strategies from a self-determination theory perspective: Implications for sports coaches. International Review of Sport and Exercise Psychology, 2, 215-233. doi:10.1080/17509840903235330 
1 Bartholomew, K. J, Ntoumanis, N., \& Thøgersen-Ntoumani, C. (2010). The controlling interpersonal style in a coaching context: Development and initial validation of a psychometric scale. Journal of Sport \& Exercise Psychology, 32, 193-216. Retrieved from http://journals.humankinetics.com/jsep

Blais, M.R., Lachance, L., Vallerand, R.J., Brière, N.M., \& Riddle, A.S. (1993). L’inventaire des motivations au travail de Blais (The work motivation inventory). Revue Québécoise de Psychologie, 14, 185-215. Retrieved from www.rqpsy.qc.ca/

Bradburn, N. M. (1969). The structure of psychological well-being. Chicago: Aldine.

Curran, P.J., \& Bauer, D.J. (2011). The disaggregation of within-person and between-person effects in longitudinal models of change. Annual Review of Psychology, 62, 586-619. doi:10.1146/annurev.psych.093008.100356

Curran, P.J., Bauer, D.J., \& Willoughby, M.T. (2006). Testing and probing interactions in hierarchical linear growth models. In C. S. Bergeman \& S. M. Boker (Eds.), The Notre Dame Series on Quantitative Methodology: Vol. 1. Methodological issues in aging research (pp. 99-129). Mahwah, NJ: Erlbaum.

Deci, E. L., \& Ryan, R. M. (2000). The “what” and "why” of goal pursuits: Human needs and the self-determination of behavior. Psychological Inquiry, 11, 227-268. doi:10.1207/S15327965PLI1104_01

Deci, E.L., Spiegel, N.H., Ryan, R.M., Koestner, R., \& Kauffman, M. (1982). Effects of performance standards on teaching styles: Behavior of controlling teachers. Journal of Educational Psychology, 74, 852-859. doi: http://dx.doi.org/10.1037/0022$\underline{0663.74 .6 .852}$

Diener, E. (1994). Assessing subjective well-being: Progress and opportunities. Social Indicators Research, 31, 103-157. doi:10.1007/BF01207052 
1 Diener, E. (2000). Subjective well-being: The science of happiness and a proposal for a national index. American Psychologist, 55, 34-43. doi:10.1037//0003-066X.55.1.34

Dixon, M.A. \& Warner, S. (2010). Employee satisfaction in sport: Development of a multidimensional model in coaching. Journal of Sport Management, 24, 139-168. Retrieved from http://journals.humankinetics.com/jsm

Forgas, J. P. (2002). Feeling and doing: Affective influences on interpersonal behavior. Psychological Inquiry, 13, 1-28. doi:10.1207/S15327965PLI1301_01.

Fraser-Thomas, J., \& Côté, J. (2009). Understanding adolescents’ positive and negative developmental experiences in sport. The Sport Psychologist, 23, 3-23. Retrieved from http://journals.humankinetics.com/tsp

Gagné, M., Ryan, R. M., \& Bargmann, K. (2003). Autonomy support and need satisfaction in the motivation and well-being of gymnasts. Journal of Applied Sport Psychology, 15, 372-390. doi:10.1080/714044203

Goodger, K., Gorely, T., Lavellee, D., \& Harwood, C. (2007). Burnout in sport: A systematic review. The Sport Psychologist, 21, 127-151. Retrieved from http://journals.humankinetics.com/tsp

Gunnell, K.E., Crocker, P.R.E., Mack, D.E., Wilson, P.M., \& Zumbo, B.D. (2014). Goal contents, motivation, psychological need satisfaction, well-being and physical activity: A test of self-determination theory over 6 months. Psychology of Sport and Exercise, 15, 19-29. http://dx.doi.org/10.1016/j.psychsport.2013.08.005

Hakanen, J. J., Bakker, A. B., \& Schaufeli, W. B. (2006). Burnout and work engagement among teachers. Journal of School Psychology, 43, 495-513. doi:10.1016/j.jsp.2005.11.001

Hox, J. J. (2010). Multilevel analysis: Techniques and applications ( $2^{\text {nd }}$ ed.). New York, NY: Routledge. 
1 Kahneman, D., Diener, E., \& Schwarz, N. (Eds.). (1999). Well-being: The foundations of hedonic psychology. New York: Russell Sage Foundation.

Klussman, U., Kunter, M., Trautwein, U., Lüdtke, O., \& Baumert, J. (2008). Teachers’ occupational well-being and quality of instruction: The important role of self-regulatory patterns. Journal of Educational Psychology, 100, 702-715. doi:10.1037/00220663.100.3.702

Mack, D.E., Wilson, P.M., Oster, K.G., Kowlaski, K.C., Crocker, P.R.E., \& Sylvester, B.D. (2011). Well-being in volleyball players: Examining the contributions of independent and balanced psychological need satisfaction. Psychology of Sport and Exercise. 12, 533-539. doi:10.1016/j.psychsport.2011.05.006

Mageau, G. A., \& Vallerand, R. J. (2003). The coach-athlete relationship: A motivational model. Journal of Sports Sciences, 21, 883-904. doi:10.1080/0264041031000140374

Ntoumanis, N. (2005) A prospective study of participation in optional school physical education using a self-determination theory framework. Journal of Educational Psychology, 97, 444-453. doi: 10.1037/0022-0663.97.3.444

Olusoga, P., Butt, J., Hays, K., \& Maynard (2009). Stress in elite sports coaching: Identifying stressors. Journal of Applied Sport Psychology, 21, 442-459. doi:1080/10413200903222921

Pelletier, L.G., Fortier, M.S., Vallerand, R.J., \& Briere, N.M. (2001). Associations among perceived autonomy support, forms of self-regulation, and persistence: A prospective study. Motivation and Emotion, 25, 279_306. doi: 10.1023/A:1014805132406

Pelletier, L.G., Séguin-Lévesque, C., \& Legault, L. (2002). Pressure from above and pressure from below as determinants of teachers' motivation and teaching behaviors. Journal of Educational Psychology, 94, 186-196. doi: 10.1037//0022-0663.94.1.186 
1 Quested, E. \& Duda, J.L. (2011). Antecedents of burnout among elite dancers: A longitudinal test of basic needs. Psychology of Sport and Exercise, 12, 159-167. doi:10.1016/j.psychsport.2010.09.003

Raedeke, T. D., (1997). Is athlete burnout more than just stress? A sport commitment perspective. Journal of Sport \& Exercise, Psychology, 19, 396-417. Retrieved from http://journals.humankinetics.com/jsep

Raedeke, T. D., \& Smith, A. L. (2001). Development and preliminary validation of an athlete burnout measure. Journal of Sport \& Exercise Psychology, 23, 281-306. Retrieved from http://journals.humankinetics.com/jsep

Rasbash, J., Browne, W., Healy, M., Cameron, B., \& Charlton, C. (2012) MLwiN Version 2.25. Centre for Multilevel Modelling, University of Bristol.

Raudenbush, S. W., \& Bryk, A. S. (2002). Hierarchical linear models (2 ${ }^{\text {nd }}$ ed.). Thousand Oaks, CA: Sage.

Reeve, J., Bolt, E., \& Cai, Y. (1999). Autonomy-supportive teachers: How they teach and motivate students. Journal of Educational Psychology, 9, 537-548. doi:10.1037/0022$\underline{0663.91 .3 .537}$

Reeve, J. \& Jang, H. (2006). What teachers say and do to support students’ autonomy during a learning activity. Journal of Educational Psychology, 98, 209-218. doi:10.1037/00220663.98.1.209

Reeve, J., Jang, H., Carrell, D., Jeon, S., \& Barch, J. (2004). Enhancing students’ engagement by increasing teachers’ autonomy support. Motivation and Emotion, 28, 147-169. doi:10.1023/B:MOEM.0000032312.95499.6f

Reynolds, W. M. (1982). Development of reliable and valid short forms of the MarloweCrowne social desirability scale. Journal of Clinical Psychology, 38, 119-125. doi:10.1002/1097-4679(198201)38:1<119::AID-JCLP2270380118>3.0.CO;2-I 
1 Rogasa, D.R. (1995). Myths about longitudinal research. In J. Gottman (Ed.), The Analysis of Change (pp. 2-65). Hillsdale, NJ: Erlbaum

Roth, G., Assor, A., Kanat-Maymon, Y., \& Kaplan, H. (2007). Autonomous motivation for teaching: How self-determined teaching may lead to self-determined learning. Journal of Educational Psychology, 99, 761-774. doi:10.1037/0022-0663.99.4.761

Ryan, R. M., \& Deci, E. L. (2001). On happiness and human potentials: A review of research on hedonic and eudaimonic well-being. Annual Review of Psychology, 52, 141-166. Retrieved from http://www.annualreviews.org/loi/psych

Ryan, R. M., \& Deci, E. L. (2002). An overview of self-determination theory. In E. L. Deci \& R. M. Ryan (Eds.),Handbook of self-determination research (pp. 3-33). Rochester, NY: University of Rochester Press.

Ryan, R. M., \& Frederick, C. M. (1997). On energy, personality and health: Subjective vitality as a dynamic reflection of well-being. Journal of Personality, 65, 529-565. doi:10.1111/j.1467-6494.1997.tb00326.x

Ryff, C. D., Love, G. D., Urry, H. L., Muller, D., Rosenkranz, M. A., Friedman, E. M., Davidson, R. J., \& Singer, B. (2006). Psychological well-being and ill-being: Do they have distinct or mirrored biological correlates? Psychotherapy and Psychosomatics, 75, 85-95. doi: 10.1159/000090892

Sheldon, K. M., \& Bettencourt, B. A. (2002). Psychological need-satisfaction and subjective well-being within social groups. British Journal of Social Psychology, 41, 25-38. Retrieved from http://www.bpsjournals.co.uk/journals/bjsp/

Silk, J.S., Morris, A.S., Kanaya, T., \& Steinberg, L. (2003). Psychological control and autonomy granting: Opposite ends of a continuum or distinct constructs? Journal of Research on Adolescence, 13, 113-128. 
1 Singer, J.D. \& Willett, J.B. (2003). Applied longitudinal data analysis: Modeling change and event occurrence. New York: Oxford University Press

Soenens, B., Sierens, E., Vansteenkiste, M., Dochy, F., \& Goossens, L. (2012). Psychologically controlling teaching: Examining outcomes, antecedents, and mediators. Journal of Educational Psychology. 104, 108-120. doi:10.1037/a0025742

Spector, P. E. (2006). Method variance in organizational research: Truth or urban legend? Organizational Research Methods, 9, 221-232. doi:10.1177/1094428105284955

Standage, M., Duda, J.L., \& Ntoumanis, N. (2005). A test of self-determination theory in school physical education. British Journal of Educational Psychology, 75, 411-433. doi: 10.1348/000709904X22359

Stebbings, J., Taylor, I. M., Spray, C. M., \& Ntoumanis (2012). Antecedents of perceived coach interpersonal behaviors: The coaching environment and coach psychological well- and ill-being. Journal of Sport \& Exercise Psychology. Retrieved from http://journals.humankinetics.com/jsep

Strahan, R., \& Gerbasi, K. C. (1972). Short, homogeneous versions of the Marlowe-Crowne social desirability scale. Journal of Clinical Psychology, 28, 191-193. doi:10.1002/1097-4679(197204)28:2<191::AID-JCLP2270280220>3.0.CO;2-G

Taylor, I. M., Ntoumanis, N., \& Standage, M. (2008). A self-determination theory approach to understanding the antecedents of teachers' motivational strategies in physical education. Journal of Sport \& Exercise Psychology, 30, 75-94. Retrieved from http://journals.humankinetics.com/jsep

Thomas, J.R, Nelson, J.K. \& Silverman, S.J. (2011). Research methods in physical activity (6 ${ }^{\text {th }}$ Ed.). Champaign, IL: Human Kinetics. 
1 Trepanier, S, Fernet, C., \& Austin, S. (2012). Social and motivational antecedents of perceptions of transformational leadership: A self-determination theory perspective. Canadian Journal of Behavioural Science, 44, 272-277. doi: 10.1037/a0028699

Vallerand, R. J., \& Losier, G. F. (1999). An integrative analysis of intrinsic and extrinsic motivation in sport. Journal of Applied Sport Psychology, 11, 142-169. doi:10.1080/10413209908402956

Vealey, R. S., Armstrong, L., Comar, W., \& Greenleaf, C.A. (1998). Influence of perceived coaching behaviors on burnout and competitive anxiety in female college athletes. Journal of Applied Sport Psychology, 10, 297-318. doi:10.1080/10413209808406395

Vansteenkiste, M., Niemiec, C. P., \& Soenens, B. (2010). The development of the five minitheories of self-determination theory: An historical overview, emerging trends, and future directions. In T. C. Urdan \& S. A. Karabenick (Eds.), Advances in motivation and achievement, v. 16A-The decade ahead: Theoretical perspectives on motivation and achievement (pp. 105-165). London: Emerald Group Publishing Limited.

Waterman, A. S. (1993). Two conceptions of happiness: Contrasts of personal expressiveness (eudaimonia) and hedonic enjoyment. Journal of Personality and Social Psychology, 64, 678-691. doi:10.1037/0022-3514.64.4.678

Watson, D., Tellegen, A., \& Clark, L. (1988). Development and validation of brief measures of positive and negative affect: The PANAS scales. Journal of Personality and Social Psychology, 54, 1063-1070. doi:10.1037/0022-3514.54.6.1063

Williams, G. C., Grow, V. M., Freedman, Z. R., Ryan, R. M., \& Deci, E. L. (1996). Motivational predictors of weight loss and weight-loss maintenance. Journal of Personality and Social Psychology, 70, 115-126. doi:10.1037/0022-3514.70.1.115 
Running head: COACHES’ PSYCHOLOGICAL HEALTH AND INTERPERSONAL STYLES

1 Table 1

2 Descriptive Statistics, Cronbach's Alpha Coefficients, and Intraclass Correlation Coefficients (ICCs) of all Study Variables

\begin{tabular}{lccccccccccc}
\hline & \multicolumn{4}{c}{ Time Point One } & \multicolumn{3}{c}{ Time Point Two } & \multicolumn{3}{c}{ Time Point Three } & ICC \\
\hline Variable & Range & $\boldsymbol{M}$ & $\boldsymbol{S D}$ & $\boldsymbol{\alpha}$ & $\boldsymbol{M}$ & $\boldsymbol{S D}$ & $\boldsymbol{\alpha}$ & $\boldsymbol{M}$ & $\boldsymbol{S D}$ & $\boldsymbol{\alpha}$ & \\
Positive Affect & 1 to 5 & 4.16 & .54 & .85 & 4.10 & .63 & .91 & 4.05 & .72 & .93 & .62 \\
Integration & 1 to 7 & 5.41 & 1.25 & .90 & 5.33 & 1.13 & .86 & 5.54 & 1.20 & .89 & .62 \\
Negative Affect & 1 to 5 & 1.68 & .62 & .86 & 1.66 & .70 & .89 & 1.55 & .56 & .86 & .65 \\
Devaluation & 1 to 5 & 1.64 & .74 & .85 & 1.70 & .78 & .86 & 1.76 & .93 & .92 & .69 \\
Autonomy Supportive Behaviors & 1 to 7 & 5.90 & .77 & .83 & 5.86 & .82 & .87 & 5.95 & .72 & .80 & .70 \\
Controlling Behaviors & 1 to 7 & 2.03 & .77 & .83 & 1.99 & .84 & .88 & 1.87 & .73 & .85 & .70 \\
Social Desirability Index & 1 to 10 & 7.14 & 1.87 & .56 & 6.94 & 1.91 & .58 & 7.13 & 1.99 & .63 & .66 \\
\hline
\end{tabular}


1 Table 2

2 Multilevel Regression Models Exploring Within-Person and Individual Difference Variability in Well-and Ill-Being as Predictors of Autonomy

3 Supportive and Controlling Interpersonal Styles.

\begin{tabular}{|c|c|c|c|c|}
\hline \multirow[b]{2}{*}{ Predictors } & \multicolumn{2}{|c|}{ Model A: Autonomy Support } & \multicolumn{2}{|c|}{ Model B: Control } \\
\hline & $\boldsymbol{\beta}$ & SE & $\beta$ & SE \\
\hline Intercept & 5.97 & $.04 * * *$ & 1.90 & $.05^{* * *}$ \\
\hline Sport Type & -.26 & $.09 * *$ & .32 & $.10^{* *}$ \\
\hline Coach Experience & .01 & .04 & N/A & N/A \\
\hline Hours Per Week Coaching & .11 & $.04 * *$ & N/A & N/A \\
\hline Social Desirability & .12 & $.05 *$ & -.04 & .05 \\
\hline \multicolumn{5}{|l|}{ Within-Person Changes } \\
\hline Positive Affect & .11 & $.04 * *$ & -.01 & .05 \\
\hline Integration & .13 & $.05 * *$ & .00 & .04 \\
\hline Negative Affect & -.01 & .04 & .10 & $.05 *$ \\
\hline Devaluation & -.06 & .04 & .06 & .05 \\
\hline \multicolumn{5}{|l|}{ Between-Person Differences } \\
\hline Positive Affect & .37 & $.06 * * *$ & -.05 & .07 \\
\hline Integration & .19 & $.05 * * *$ & .02 & .06 \\
\hline Negative Affect & -.03 & .05 & .29 & $.06 * * *$ \\
\hline Devaluation & .09 & .06 & .08 & .07 \\
\hline \multicolumn{5}{|l|}{ Random Effects } \\
\hline Within-Person Integration & .17 & $.05 * * *$ & N/A & N/A \\
\hline Within-Person Negative Affect & N/A & N/A & .10 & $.04 *$ \\
\hline
\end{tabular}

$4 \quad$ Note. ${ }^{*} \mathrm{p}<.05 ; * * \mathrm{p}<.01, * * * \mathrm{p}<.001$ 